(C) 2021, The Authors. Published by Elsevier Inc. and Fass Inc. on behalf of the American Dairy Science Association ${ }^{\circledR}$. This is an open access article under the CC BY-NC-ND license (http://creativecommons.org/licenses/by-nc-nd/4.0/).

\title{
Effect of body condition change and health status during early lactation on performance and survival of Holstein cows
}

\author{
D. Manríquez, ${ }^{1} \odot$ W. W. Thatcher, ${ }^{2} \odot$ J. E. P. Santos, ${ }^{2} \odot$ R. C. Chebel, ${ }^{3} \odot$ K. N. Galvão, ${ }^{3} \odot$ \\ G. M. Schuenemann, ${ }^{4} \odot$ R. C. Bicalho, ${ }^{5} \odot$ R. O. Gilbert, ${ }^{6} \odot$ S. Rodriguez-Zas, ${ }^{7} \oplus$ C. M. Seabury, ${ }^{8}$

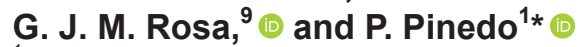 \\ ${ }^{1}$ Department of Animal Sciences, Colorado State University, Fort Collins 80521 \\ ${ }^{2}$ Department of Animal Sciences, University of Florida, Gainesville 32611 \\ ${ }^{3}$ College of Veterinary Medicine, University of Florida, Gainesville 32611 \\ ${ }^{4}$ Department of Veterinary Preventive Medicine, The Ohio State University, Columbus 43210 \\ ${ }^{5}$ College of Veterinary Medicine, Cornell University, Ithaca, NY 14850 \\ ${ }^{6}$ School of Veterinary Medicine, Ross University, St. Kitts, West Indies \\ ${ }^{7}$ Department of Animal Sciences, University of Illinois, Urbana-Champaign 61801 \\ ${ }^{8}$ College of Veterinary Medicine, Texas A\&M University, College Station 77843 \\ ${ }^{9}$ Department of Animal and Dairy Sciences, University of Wisconsin, Madison 53706
}

\begin{abstract}
Body condition score (BCS) and disease records are commonly available in dairy operations. However, the effect of BCS changes $(\triangle B C S)$ considering specific health profiles has not been investigated extensively. The objective of this study was to assess the effects of different levels of $\triangle \mathrm{BCS}$ on fertility, milk yield, and survival of Holstein cows diagnosed with reproductive disorders (REP; dystocia, twins, retained fetal membranes, metritis, and clinical endometritis), other health disorders (OTH; subclinical ketosis, left displaced abomasum, lameness, clinical mastitis, and respiratory disease), or with no disease events (HLT) within 40 days in milk (DIM). Data included lactation information from 11,733 cows calving between November 2012 and October 2014 in 16 herds across 4 geographical regions in the United States (Northeast, Midwest, Southwest, Southeast). Cows were evaluated for BCS at $5 \pm 3$ DIM (BCS5) and at $40 \pm 3$ DIM (BCS40) and the difference between BCS40 and BCS5 was classified as excessive loss of BCS (EL; $\triangle \mathrm{BCS} \leq-0.75$ ), moderate loss (ML; $\triangle \mathrm{BCS}=-0.5$ to -0.25$)$, no change $(\mathrm{NC} ; \Delta \mathrm{BCS}=$ 0 ), or gain of BCS (GN; $\triangle \mathrm{BCS} \geq 0.25$ ). Multivariable logistic regression was used for assessing potential associations between the outcomes of interest and $\triangle \mathrm{BCS}$ and health. The effect of the interaction term $\triangle B C S$ by health group was not statistically significant for any of the study outcomes. The odds of resumption of ovarian cyclicity (ROC), in GN, NC, and ML cows were 1.94 (95\% CI: 1.57-2.40), 1.59 (1.28-1.97), and
\end{abstract}

Received December 26, 2020.

Accepted August 11, 2021.

*Corresponding author: pablo.pinedo@colostate.edu
$1.27(1.10-1.47)$ times greater than the odds of ROC in EL cows, respectively. The odds of pregnancy at 150 DIM (P150) in GN cows were $1.61(1.20-2.17)$ times greater than the odds of P150 in EL cows. Cows with REP or OTH disorders had smaller odds of ROC compared with HLT cows [REP: OR $=0.65(0.56-0.76)$ and OTH: OR $=0.79(0.68-0.92)]$. For pregnancy outcomes, REP cows had smaller odds of pregnancy at the first artificial insemination compared with HLT cows [0.70 (0.58-0.84)]. Similarly, REP cows had smaller odds of being diagnosed pregnant by 150 and 305 DIM compared with HLT cows [P150: $0.73(0.59-0.87)$, P305: $0.58(0.49-0.69)]$. Overall, average daily milk within the first $90 \mathrm{DIM}$ was greater in EL $(39.5 \pm 1.13 \mathrm{~kg} / \mathrm{d})$ and $\mathrm{ML}(38.9 \pm 1.11 \mathrm{~kg} / \mathrm{d})$ cows than in NC $(37.8 \pm 1.12$ $\mathrm{kg} / \mathrm{d})$ and GN $(36.2 \pm 1.12 \mathrm{~kg} / \mathrm{d})$ cows. On the other hand, average daily milk within the first 90 DIM was lower in REP $(37.0 \pm 1.11 \mathrm{~kg} / \mathrm{d})$ cows compared with OTH $(38.7 \pm 1.12 \mathrm{~kg} / \mathrm{d})$ and HLT cows $(38.6 \pm 1.11$ $\mathrm{kg} / \mathrm{d})$. The magnitude of $\triangle \mathrm{BCS}$ and the health status of early lactation cows should be considered when assessing subsequent cow performance and survival.

Key words: body condition, disease, fertility, culling

\section{INTRODUCTION}

After calving, most cows exhibit low DMI coupled with increased demand for nutrients to support the onset of lactation, resulting in levels of energy intake that do not meet the energetic requirements for lactation (Gross et al., 2011). The ensuing negative energy balance (NEB) triggers mobilization of fat, labile protein, and calcium toward the mammary gland through homeorhetic mechanisms (Bauman and Currie, 1980; Lean et al., 2013). 
This environment of decreased DMI and metabolic changes around calving has been associated with reduced innate immune response (Sander et al., 2011; Kasimanickam et al., 2013; Beltman et al., 2020), increased serum concentrations of fatty acids (FA), BHB, and acute-phase proteins (Bicalho et al., 2017; Folnozic et al., 2019; Stevenson et al., 2020), body condition loss, and impaired health status during transition (Chebel et al., 2018; Stevenson et al., 2020).

Low BCS at calving is associated with decreased milk yield and reduced likelihood of pregnancy, whereas overconditioning at calving is associated with greater probability of postpartum metabolic diseases (Roche et al., 2009). Moreover, the magnitude in the change in BCS ( $\triangle$ BCS) following dry-off and during the transition period has been established as a relevant factor affecting subsequent fertility, health, and survival (Carvalho et al., 2014; Chebel et al., 2018) and the association between overconditioning at dry-off and lesser DMI and time feeding, together with greater loss in BCS, has been recently reported (Daros et al., 2021). In a study by Barletta et al. (2017), loss of BCS during the transition period reduced pregnancy/AI and percentage of cyclic cows at 50 DIM. In addition, cows that lost BCS during the transition period had more health complications than cows that gained or maintained BCS. Moreover, Carvalho et al. (2014) established that cows with the greatest BCS loss during early postpartum displayed increased impairments of embryo development during the first week after AI.

Compromised postpartum health has a negative effect on performance and survival of dairy cows and occurrences of uterine, metabolic, and other health disorders have been identified extensively as risk factors for lower subsequent fertility and milk yield and higher risk of culling (Santos et al., 2010; Ribeiro et al., 2013; Carvalho et al., 2019; Mohtashamipour et al., 2020).

The interrelationship between loss in BCS and occurrence of disease is complex and establishing precise cause and effect associations is challenging. Stevenson et al. (2020) reported increased risk of milk fever, ketosis, fatty liver, metritis, digestive disorders, and mastitis in cows with greater loss of BCS after calving. Moreover, Gärtner et al. (2019) indicated that high-mobilizing cows, irrespective of parity, were less able to overcome metabolic challenges during the early postpartum, as evidenced by higher postpartum serum FA and BHB concentrations and lower milk yield. Conversely, diseases that are associated with reduced feeding time and decreased DMI would result in increased loss of body reserves (Bach et al., 2007; Miguel-Pacheco et al., 2014) and increased glucose utilization during infection (Lang and Dobrescu, 1991) would result in inefficient feed utilization, due to the energetic input for the immune response (Lochmiller and Deerenberg, 2000; Kvidera et al., 2017).

Although this evidence supports the idea of a combined effect of disease concurrence and the extent of BCS loss on subsequent fertility and survival, this concept has not been explored widely. Changes in BCS may be used to represent the level of the NEB after calving (Roche et al., 2009), and health events can reflect impaired immune, metabolic, and homeostatic responses. Consequently, a deeper observation of cows with specific profiles of $\triangle B C S$ and health statuses may assist in management for reproductive, lactation, and culling decisions after transition.

We hypothesized a greater detrimental effect of postpartum negative $\triangle B C S$ on performance and survival when Holstein cows were diagnosed with specific health disorders. Therefore, the objective of this study was to assess effects of different levels of $\triangle \mathrm{BCS}$ between 5 and 40 DIM on fertility [resumption of ovarian cyclicity (ROC), pregnancy at the first AI (PAI1), pregnancy loss at $60 \mathrm{~d}$ of gestation, pregnancy at 150 DIM (P150) and pregnancy at 305 DIM (P305)], average daily milk within the first 90 DIM (M90), and live culling or death after 40 DIM (CD) in cows diagnosed with reproductive disorders (REP; dystocia, twins, retained fetal membranes, metritis, and clinical endometritis), other health disorders (OTH; subclinical ketosis, left displaced abomasum, lameness, clinical mastitis, and respiratory disease), or healthy with no disease events (HLT) within 40 DIM.

\section{MATERIALS AND METHODS}

\section{Study Design and Study Population}

A retrospective cohort study used information from 11,733 Holstein cows to assess the effect of $\triangle B C S$ and health status during the first 40 DIM on fertility, milk yield, and survival of Holstein cows. The data set originated from a study investigating the association between genomic variation and fertility of Holstein cows performed in 16 herds across the United States (Lopes et al., 2020; Pinedo et al., 2020a). The participating herds were distributed across 7 states (California, Florida, Minnesota, New York, Ohio, Texas, and Wisconsin). All herds used freestall barns or dry lots with shades. The voluntary waiting period ranged from 40 to 70 DIM, and breeding management included combinations of timed AI and heat detection. Milking frequency ranged from 2 to 4 milkings per day in herringbone, parallel, and rotatory parlors. Fifteen herds used fans or sprinklers as heat abatement systems (Pinedo et al., 2020a). 
Study cows were enrolled at parturition, with half of the calvings occurring during the warm season (May to August) and half in the cool season (October to January), with a $33 \%$ targeted inclusion of primiparous cows. Following enrollment, study cows were monitored weekly for disease occurrence, reproductive events, culling, and death. The data set contained completed lactations from cows calving from November 2012 to October 2014 and included herd, date of calving, lactation number, calving-related events, and average daily milk yield within the first 90 DIM.

\section{Explanatory Variables}

Cows were evaluated for BCS at $5 \pm 3$ DIM (BCS5) and at $40 \pm 3$ DIM (BCS40) using a 1 (severe under conditioning) to 5 (severe over conditioning) point scale with 0.25-point increments as described by Ferguson et al. (1994). Additionally, values for BCS5 and BCS40 were categorized as described by Ylioja et al. (2019) as low $(<2.75)$, moderate (2.75 to 3.5$)$, high (3.75 to $4.25)$, and excessive (>4.25) BCS. Furthermore, based on the numerical difference between BCS40 and BCS5 $(\triangle \mathrm{BCS})$, cows were assigned to one of the following categories: excessive loss of BCS (EL; $\triangle \mathrm{BCS} \leq-0.75$ ); moderate loss ( $\mathbf{M L} ; \Delta \mathrm{BCS}=-0.5$ to -0.25 ); no change $(\mathbf{N C} ; \triangle \mathrm{BCS}=0)$, or gain of BCS $(\mathbf{G N} ; \triangle \mathrm{BCS}$ $\geq 0.25$; Chebel et al., 2018). Cows $(\mathrm{n}=541 ; 4.6 \%)$ that were not body condition scored at 40 DIM due to live culling or death were not considered in the analyses.

Monitoring of disease and body condition scoring was performed during weekly visits to the study farms by the authors (i.e., investigator veterinarians and graduate students). Cows were inspected using headlocks or sorting gates after cows returned from the milking parlors. Periodic training and evaluation of the research personnel completing body condition scoring was performed in each of the locations. Calving-related events (dystocia, twins, retained fetal membranes), as well as left displaced abomasum, mastitis, and respiratory disease were obtained from farm records stored in on-farm software. Only health events diagnosed within the first 40 DIM were considered in the analyses. Health-related events were categorized into REP (dystocia, twins, retained fetal membranes, metritis, and clinical endometritis) and OTH (subclinical ketosis, left displaced abomasum, lameness, clinical mastitis, and respiratory disease) depending on the first health disorder occurred in lactation. A third category included unaffected cows classified as healthy (HLT).

Briefly, the diagnosis criteria were as follows: dystocia was determined using the calving ease score of 1 (spontaneous or normal) to 5 (extremely difficult), in which calving ease scores $\geq 3$ were considered as dystocia (Mee, 2008; Vieira-Neto et al., 2017). Retained fetal membranes was diagnosed when cows failed to release fetal membranes within $24 \mathrm{~h}$ after calving. The diagnosis of metritis and clinical endometritis were performed using the Metricheck device (Metricheck, SimcroTech) considering a vaginal discharge score of 0 to $5(0=$ no mucus; $1=$ crystalline; $2=$ flecks of pus; $3=$ mucopurulent $<50 \%$ pus; $4=$ purulent, $>50 \%$ pus; $5=$ watery, reddish or brownish fetid discharge; McDougall et al., 2007). Cases of metritis were diagnosed at $7 \pm 3$ DIM by having a vaginal discharge score 5 , independent of fever, whereas clinical endometritis was evaluated at 28 \pm 7 DIM diagnosed by a vaginal discharge score 3 to 4 (Sheldon et al., 2006; McDougall et al., 2007). Screening for subclinical ketosis was performed at $7 \pm 3 \mathrm{DIM}$ by BHB serum concentration $>1.0 \mathrm{mmol} / \mathrm{L}$ (Overton et al., 2017). Lameness was assessed at $35 \pm 3$ DIM using the 1 (normal locomotion) to 5 (nonweight-bearing lame) visual locomotion scoring described by Bicalho et al. (2007). Cows with locomotion scores $>2$ were considered lame. Farms' records of displaced abomasum, mastitis, and respiratory disease were available in the data set and categorized as binary variables.

Parity was created as a binary variable including multiparous (MP; lactation number $\geq 2$ ) and primiparous $(\mathbf{P P}$; lactation number $=1)$ cows. Season of calving was categorized in spring, summer, fall, or winter according to the calving date. Finally, a milk yield category was added as a covariate in the models for pregnancy at 150 DIM and pregnancy at 305 DIM using the quartile distribution of the average daily milk yield in the first 90 DIM. Cows below the lower quartile were classified as low M90, cows between the lower and upper quartile were classified as medium M90, and cows in the upper quartile of M90 were classified as high M90.

\section{Study Outcomes}

This study comprised fertility, milk yield, and survival outcomes. Fertility and survival variables were measured after 40 DIM. Milk yield was assessed using the average daily milk yield in the first 90 DIM, calculated from on-farm daily recording of milk yield or from monthly DHI test days. Fertility outcomes included ROC by $54 \pm 3$ DIM (cycling $=1$, noncycling $=0$ ), PAI1 (pregnant $=1$, nonpregnant $=0$ ), pregnancy loss at $60 \mathrm{~d}$ of gestation (pregnancy loss $=1$, reconfirmed pregnant $=0), \mathrm{P} 150($ pregnant $=1$, nonpregnant $=0)$ and P305 (pregnant $=1$, nonpregnant $=0$ ). The M90 was calculated as the average of milk yield $(\mathrm{kg} / \mathrm{d})$ on the test days that occurred within the first 90 DIM. Finally, CD events (live culling or death $=1$, survived $=$ 
0) that occurred from 40 until 305 DIM were combined in one category; the DIM at culling or death event were available in the data set.

The ROC was assessed via transrectal ultrasonography (portable ultrasounds equipped with $7.5 \mathrm{MHz}$ linear transducer), at both $40 \pm 3$ and $54 \pm 3$ DIM. Anovulation was determined when a corpus luteum was not observed on both consecutive ultrasound scans (Cerri et al., 2004; Bicalho et al., 2008). Pregnancy was diagnosed via transrectal ultrasonography at $32 \pm 3 \mathrm{~d}$ after $\mathrm{AI}$ and reconfirmed at $60 \pm 3 \mathrm{~d}$ of gestation. Pregnancy loss at $60 \mathrm{~d}$ of gestation was calculated by the proportion of cows diagnosed pregnant at $32 \pm 3$ but nonpregnant at $60 \pm 3 \mathrm{~d}$ after the first or second AI. Both P150 and P305 were assessed from farm records.

\section{Statistical Analyses}

Frequency distributions of cows by geographical region (Northeast, Midwest, Southeast, and Southwest), herd, and parity category were calculated using the PROC FREQ procedure of SAS 9.4 (SAS institute Inc.). The PROC MEANS procedure was used to describe the mean and standard deviation of M90 in the study population and stratified by parity. Numerical values of BCS5, BCS40, and their differences $(\triangle \mathrm{BCS})$ were determined (mean, \pm SEM) for the overall population using one sample $t$-test (PROC TTEST) and compared by parity using the 2 sample and 2 -sided Satterthwaite test (PROC TTEST).

Descriptive time-to-event analysis for CD was performed using PROC LIFETEST. Additionally, incidence risks of REP and OTH disorders, and live culling and death were calculated using PROC FREQ. Independency between $\triangle \mathrm{BCS}$ category and health group was tested using Mantel-Haenszel chi-squared test assuming an ordinal nature in the $\triangle \mathrm{BCS}$ categories (from more severe BCS loss to BCS gain).

The relationships among multiple levels of the variables in study and potential associations affecting reproductive performance, milk yield, and combined death and live culling are illustrated in Figure 1. We developed this causal diagram to build the initial logistic regression models considering $\triangle \mathrm{BCS}$ category, health group, and their potential interaction. Controlling variables included in the models as well as unmeasured covariates are depicted in Figure 1. Parity number was categorized as primiparous and multiparous cows. Seasons of calving were categorized as spring, summer, fall, or winter according to the calving date. A milk yield category was added as a covariate in the models for P150 and P305 using the quartile distribution of M90. The potential collinearity between BCS5 and $\triangle \mathrm{BCS}$ was assessed using the corrB option of PROC GEN-
MOD. Based on the assessment of the estimated correlation matrix collinearity between BCS5 and $\triangle \mathrm{BCS}$ was not detected.

Odds ratios and predicted probabilities for all the study outcomes were estimated for all levels of the variables of interest. A forward stepwise selection approach was used considering the 4-categories of $\triangle \mathrm{BCS}$ [EL (reference), ML, NC, and GN], the 3-levels of health group [REP, OTH, and HLT (reference)], and their interaction in the initial model. The logistic equation to investigate combined effects of $\triangle B C S$ and health group can be expressed as presented by de Mutsert et al. (2009):

$$
\begin{gathered}
\ln [p /(1-p)]=\beta_{0}+\beta_{1}(\Delta \mathrm{BCS})+\beta_{2}(\mathrm{HLT}) \\
+\beta_{3}(\Delta \mathrm{BCS} \times \mathrm{HLT})
\end{gathered}
$$

where $p$ is the proportion of cows with the respective outcomes and $[p /(1-p)]$ is the odds of the outcome, $\beta_{0}$ is the model intercept for each study outcome, $\beta_{1}$ and $\beta_{2}$ are the regression parameters for $\triangle \mathrm{BCS}$ and HLT, respectively. The interaction term $\left(\beta_{3}\right)$ generated multiple comparison contrasts for the log odds for each study outcome and independency between $\triangle \mathrm{BCS}$ category and health group was tested using MantelHaenszel chi-squared test.

As the observations (lactations) were clustered in herds, in which cows had common environment and management, standard errors were corrected using herd as repeated statement. The exchangeable correlation structure was included in the procedure, which assumes the correlation to be the same among observations within a cluster (herd) (Dohoo et al., 2009). The binomial distribution, logit link, aggregate and type3 options were included in the model statement.

From the final logistic models, predicted probabilities and $95 \%$ confidence intervals were calculated using the $P=$ pred and the $\mathrm{l}=$ lower and $\mathrm{u}=$ upper options in the output statement of the procedure. Predicted probabilities from all study outcomes were modeled using PROC MIXED with $\triangle \mathrm{BCS}$ and health groups as predictors. The least squares means and standard error of the mean were plotted using the $\triangle \mathrm{BCS}$ categories in the $\mathrm{x}$-axis and health groups as data series.

Milk yield (M90) was analyzed using PROC MIXED. The initial model comprised the effects of $\triangle \mathrm{BCS}$, health group, and their interaction term. The covariates considered in the M90 model were BCS5, geographical region, parity, and season of calving. Herd was considered as random effect. Resulting least squares means for M90 were compared using the Tukey-Kramer multiple comparison test. For all outcome variables, statistically significant predictors were selected at $P$-value $<0.05$ 


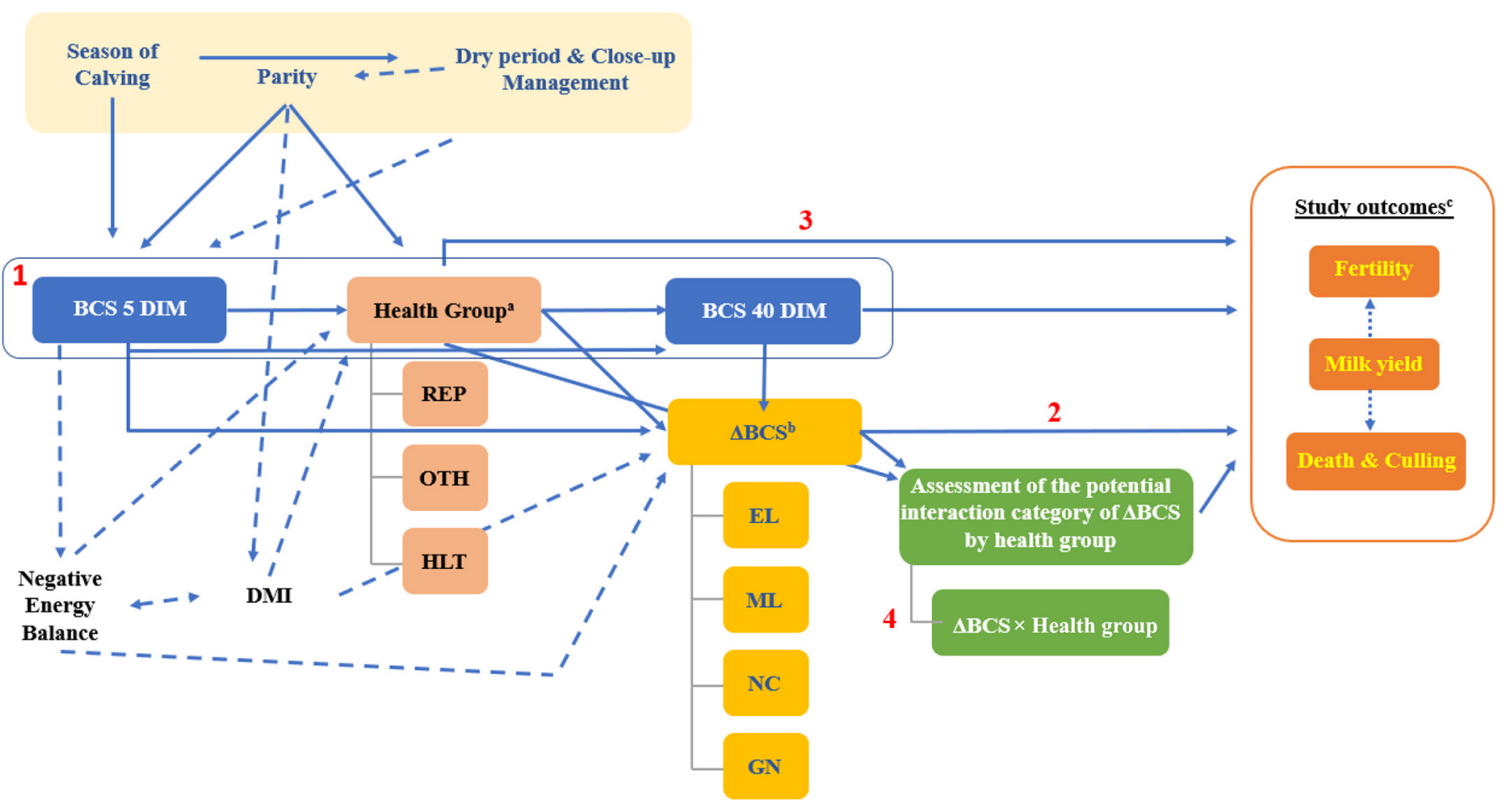

Figure 1. Causal diagram providing the rationale for multivariable logistic regression model building. (1) Monitoring period for $\Delta \mathrm{BCS}$ and disease events that extended from calving to 40 DIM. Initial explanatory variables were BCS change ( $\triangle$ BCS; 4 groups) and health group ( 3 groups). Main effects of $\triangle$ BCS category (2) and health groups (3). The potential effect of the interaction $\Delta$ BCS by health group was tested (4). Solid lines indicate associations tested in the logistic models, whereas dashed lines represent theoretical and unmeasured associations. ${ }^{a} \mathrm{REP}=$ reproductive-related events (dystocia, twins, retained fetal membranes, metritis, and clinical endometritis); OTH = other health events (subclinical ketosis, displaced abomasum, lameness, clinical mastitis, respiratory disease); HLT $=$ cows not diagnosed with REP or OTH events. ${ }^{b} \mathrm{EL}=$ excessive loss of BCS $(\triangle \mathrm{BCS}<-0.75) ; \mathrm{ML}=$ moderate loss of BCS $(\triangle \mathrm{BCS}=-0.5$ to -0.25$) ; \mathrm{NC}=$ no change of $\mathrm{BCS}(\mathrm{NC}, \Delta \mathrm{BCS}=0) ; \mathrm{GN}$ $=$ gained $\mathrm{BCS}(\triangle \mathrm{BCS} \geq 0.25) .3$. $^{\mathrm{c} S t u d y}$ outcomes included resumption of ovarian cyclicity assessed at $40 \pm 3$ and $54 \pm 3$ DIM, pregnancy after the first $\mathrm{AI}$ assessed at $32 \pm 3 \mathrm{~d}$ after $\mathrm{AI}$ and reconfirmed at $60 \pm 3 \mathrm{~d}$ of gestation, pregnancy loss assessed at $60 \pm 3 \mathrm{~d}$ of gestation, pregnancy at 150 and 305 DIM, milk yield at 90 DIM, and culling or death after 40 DIM.

Table 1. Frequency distribution and average daily milk yield at 90 DIM of Holstein cows included in the analyses; frequencies are presented by parity category and herd within region in the United States

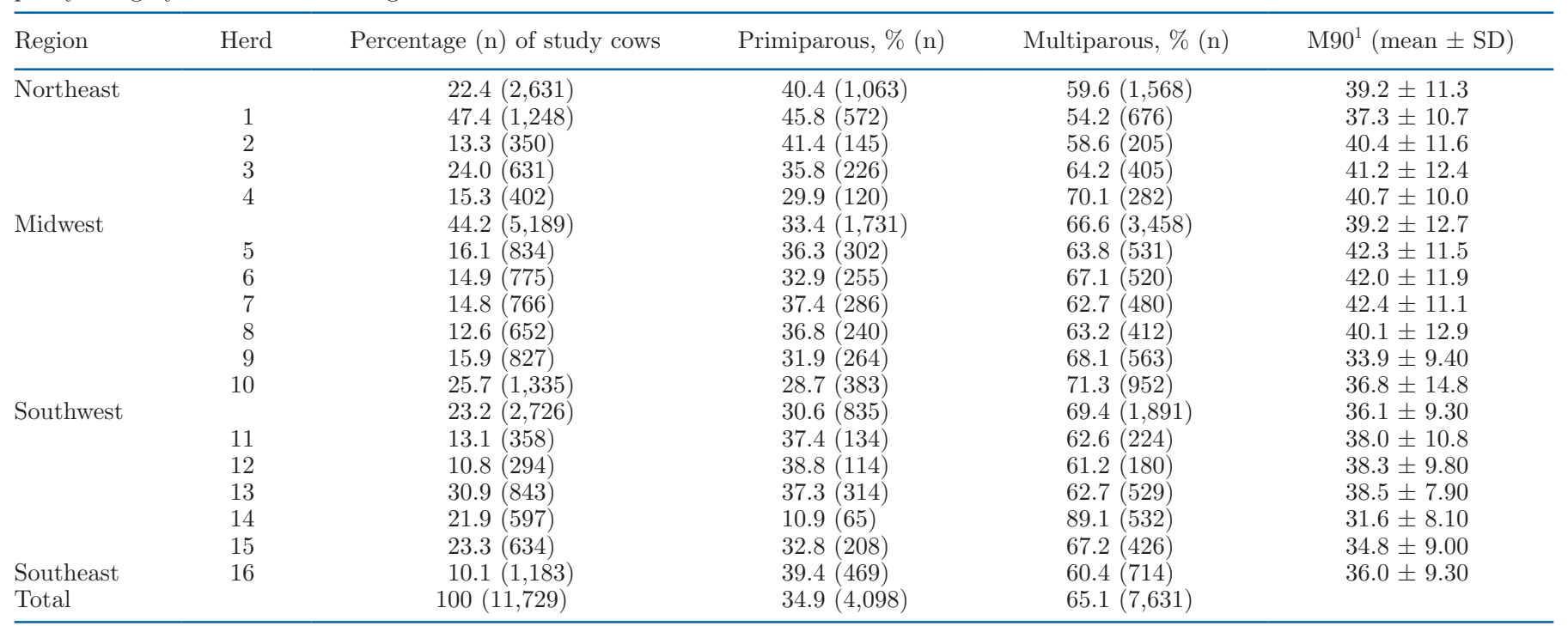

${ }^{1} \mathrm{M} 90=$ Herd average daily milk yield $(\mathrm{kg} / \mathrm{d})$ calculated from test days within the first 90 DIM. 
Table 2. Frequency distribution for reproductive outcomes and average daily milk yield up to 90 DIM for the overall study population and stratified by parity; the population included 11,729 cows located in 16 herds in 4 regions in the United States

\begin{tabular}{|c|c|c|c|c|}
\hline Study outcome & Overall & Primiparous & Multiparous & $P$-value ${ }^{1}$ \\
\hline Pregnant after first AI, \% (n) & $36.7(3,838)$ & $37.6(878)$ & $36.7(1,609)$ & 0.48 \\
\hline Pregnant at 150 DIM, \% (n) & $76.8(6,716)$ & $76.7(2,555)$ & $78.8(4,161)$ & 0.92 \\
\hline Pregnant at 305 DIM, \% (n) & $91.0(8,747)$ & $91.7(3,330)$ & $90.6(5,417)$ & 0.07 \\
\hline Milk yield up to $90 \mathrm{DIM},{ }^{3} \mathrm{~kg} / \mathrm{d}$ & $39.1 \pm 10.3$ & $32.4 \pm 7.12$ & $42.8 \pm 9.94$ & $<0.0001$ \\
\hline
\end{tabular}

${ }^{1} P$-value for the univariate analyses between study outcomes and parity.

${ }^{2}$ Ovarian cyclicity assessed at $40 \pm 3$ and at $54 \pm 3$ DIM.

${ }^{3}$ Average \pm SD.
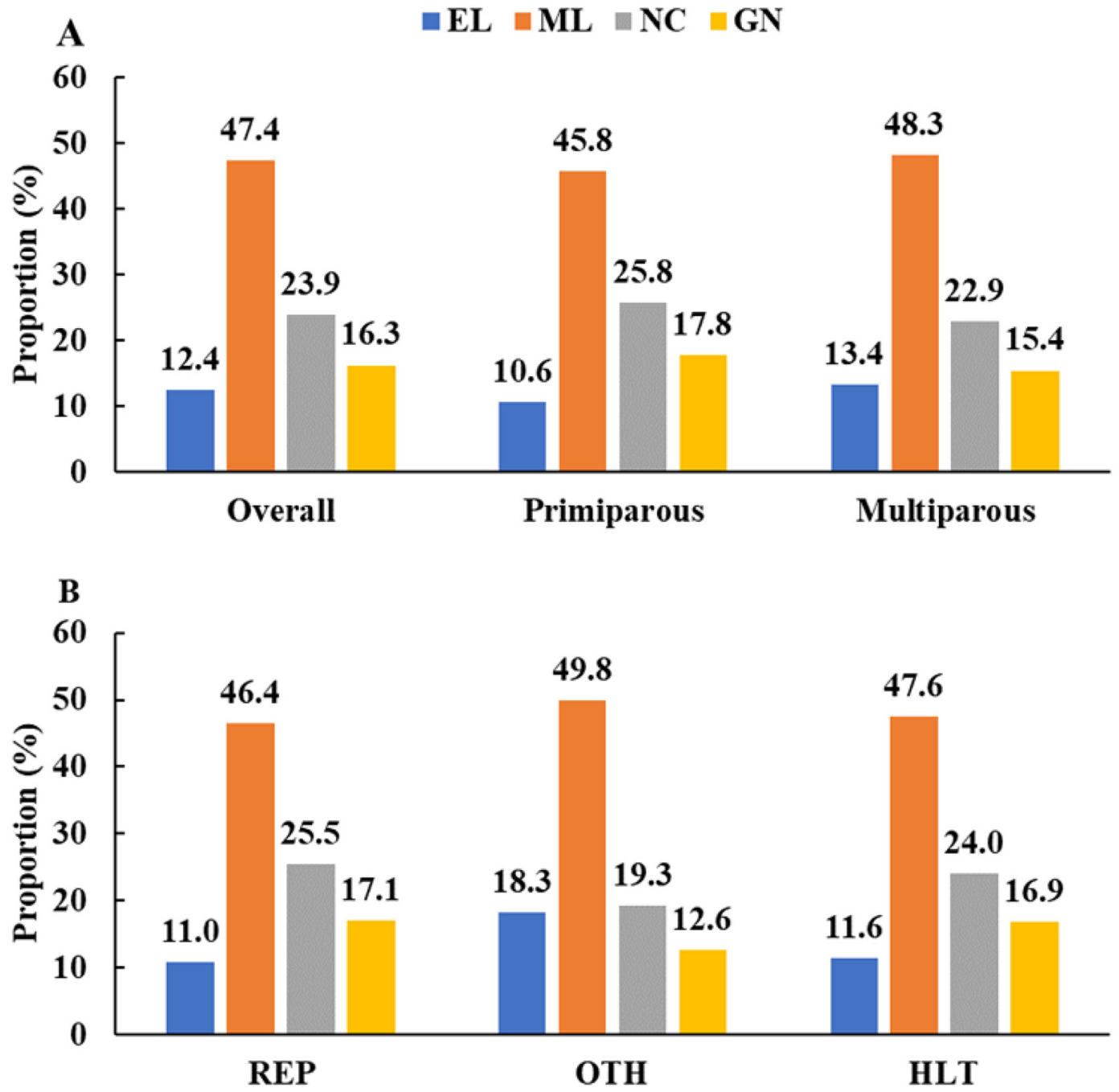

Figure 2. Proportions of the study cows classified by BCS change ( $\triangle$ BCS) from $5 \pm 3$ DIM to $40 \pm 3$ DIM, presented by parity (A) and by health-related events (B). The population included 11,729 cows located in 16 herds in 4 regions in the United States. EL $=$ excessive loss of BCS $(\Delta \mathrm{BCS} \leq-0.75) ; \mathrm{ML}=$ moderate loss of $\mathrm{BCS}(\Delta \mathrm{BCS}=-0.5$ to -0.25$) ; \mathrm{NC}=$ no change of $\mathrm{BCS}(\Delta \mathrm{BCS}=0) ; \mathrm{GN}=$ gained $\mathrm{BCS}(\Delta \mathrm{BCS}$ $\geq 0.25$ ). Total cows scored $=11,188 . \mathrm{REP}=$ reproductive-related events (dystocia, twins, retained fetal membranes, metritis, and clinical endometritis); OTH = other health-related events (subclinical ketosis, displaced abomasum, lameness, clinical mastitis, respiratory disease). HLT = cows not diagnosed with REP or OTH events. 
and controlling variables remained in the models at $P$ value $\leq 0.20$.

\section{RESULTS}

\section{Descriptive Statistics}

Four cows were removed from the data set because of missing calving dates. Due to loss of follow-up, live culling, or death, 541 cows did not have a second BCS (40 \pm 3 DIM) available. Therefore, 11,188 Holstein cows were included in the analyses. Overall, distributions of calvings across seasons were spring $16.2 \%(\mathrm{n}=1,897)$, summer $31.1 \%(\mathrm{n}=3,650)$, fall $40 \%(\mathrm{n}=4,689)$, and winter $12.7 \%(\mathrm{n}=1,493)$. Demographic information for the study population is presented in Table 1, which includes geographical location, distribution by parity, and herd average daily milk yield.

The frequency distributions of cows for each reproductive outcome and M90 by parity are presented in Table 2, while Figure 2 provides the proportions of cows classified by category of $\triangle \mathrm{BCS}$ presented by parity and by health group. In the overall population, mean $( \pm$ SEM) BCS5 and BSC40 were $3.18 \pm 0.004$ and 2.97 \pm 0.004 points, respectively, whereas the numerical difference between BCS5 and BCS40 was $-0.21( \pm 0.004)$ points. Within parity, PP cows had greater BCS40 and BCS5 compared with MP cows (BCS5, $3.22 \pm 0.006$ vs. $3.15 \pm 0.005$ points, $P<0.0001$; BCS40, $3.04 \pm$ 0.006 vs. $2.93 \pm 0.005$ points, $P<0.0001$ ). Finally, the difference between BCS40 and BCS5 was lower in PP cows compared MP cows $(-0.18 \pm 0.006$ vs. $-0.23 \pm$ 0.005 points, $P<0.0001)$.
The overall incidence risks (95\% CI) for REP, OTH, and $\mathrm{CD}$ were $49.0 \%$ (48.1-49.9), $17.1 \%$ (16.4-17.8), and $19.3 \%$ (18.6-20.0), respectively. The number of cases and the incidence risks of health-related events and live culling and death by parity category are presented in Table 3. Primiparous cows had higher incidences of dystocia, metritis, and clinical endometritis compared with MP cows, whereas MP had higher incidences of OTH disorders (except for mastitis) and twice greater incidence risk of leaving the herd (Table 3 ).

\section{Effect of $\triangle B C S$ and Health Group on Fertility}

The effect of the interaction term $\triangle B C S$ by health group was not statistically significant for any of the study outcomes. In consequence, only the results for the main effects $\triangle \mathrm{BCS}$ and health group are reported. Overall, $\triangle \mathrm{BCS}$ was associated with $\mathrm{ROC}(P=0.006)$ and P150 $(P=0.04)$. The odds of ROC, in GN, NC, and ML cows were 1.94 (95\% CI: 1.57-2.40; $P<0.0001$ ), 1.59 (1.28-1.97; $P<0.0001)$, and $1.27(1.10-1.47 ; P$ $=0.0002)$ times greater than the odds of ROC in EL cows, respectively. The odds of $\mathrm{P} 150$ in GN cows were $1.61(1.20-2.17 ; P<0.0001)$ times greater than the odds of P150 in EL cows (Table 4). The predicted probabilities (LSM and SEM) for reproductive and survival outcomes by $\triangle \mathrm{BCS}$ categories are presented in Figures 3 and 4 .

Health group within the first 40 DIM was associated with ROC $(P=0.003)$, PAI1 $(P=0.02)$, P150 $(P=$ $0.04)$, and P305 $(P=0.004)$. Cows diagnosed with REP or OTH disorders had smaller odds of ROC compared with HLT cows [REP: OR $=0.65(0.56-0.76) ; P<$

Table 3. Frequency distributions and incidence risks of health-related events (reproductive or other $\leq 40$ DIM) and live culling and death by parity category; the population included 11,729 cows located in 16 herds in 4 regions in the United States

\begin{tabular}{|c|c|c|c|c|}
\hline Study variable ${ }^{1}$ & \multicolumn{2}{|c|}{ Number of cases } & \multicolumn{2}{|c|}{ Incidence risk (95\% CI) } \\
\hline Reproductive disorders & 2,214 & 3,536 & $54.0(52.5-55.6)$ & $46.3(45.2-47.5)$ \\
\hline Twins & 35 & 452 & $0.86(0.57-1.14)$ & $5.95(5.42-6.48)$ \\
\hline Retained fetal membranes & 168 & 586 & $4.10(3.49-4.71)$ & $7.68(7.08-8.28)$ \\
\hline Metritis & 1,372 & 1,599 & $33.5(32.1-35.0)$ & $21.0(20.0-22.0)$ \\
\hline Subclinical ketosis & 781 & 1,872 & $19.5(18.3-20.7)$ & $25.1(24.2-26.1)$ \\
\hline Displaced abomasum & 24 & 223 & $0.59(0.35-0.82)$ & $2.9(2.54-3.30)$ \\
\hline Lameness & 87 & 416 & $2.23(1.77-2.70)$ & $5.88(5.33-6.43)$ \\
\hline Clinical mastitis & 428 & 748 & $10.4(9.51-11.4)$ & $9.80(9.13-10.5)$ \\
\hline Respiratory disease & 62 & 202 & $1.51(1.14-1.89)$ & $2.65(2.29-3.01)$ \\
\hline Left the herd after 40 DIM & 479 & 1,798 & $12.0(11.0-13.0)$ & $24.8(23.8-25.8)$ \\
\hline Live culling & 415 & 1,566 & $10.1(9.20-11.1)$ & $20.5(19.6-21.4)$ \\
\hline
\end{tabular}

${ }^{1}$ Metritis $=$ diagnosed at $7 \pm 3$ DIM by mucus score $=5$; clinical endometritis $=$ diagnosed at $28 \pm 7$ DIM by mucus score $>2 ;$ subclinical ketosis $=$ diagnosed at $7 \pm 3$ DIM by serum BHBA $>1.0 \mathrm{mmol} / \mathrm{L}$; lameness = diagnosed at $35 \pm 3$ DIM by lameness score $>2$. 
0.0001 and OTH: OR $=0.79(0.68-0.92) ; P=0.0007]$. For pregnancy outcomes, REP cows had smaller odds of PAI1 compared with HLT cows [0.70 (0.58-0.84); $P$ $<0.0001]$. Similarly, REP cows had smaller odds of being diagnosed pregnant by 150 and 305 DIM compared with HLT cows [P150: 0.73 (0.59-0.87); $P<0.0001$, P305: 0.58 (0.49-0.69); $P<0.0001]$. The OTH cows did not differ in PAI1, or P150 and P305 DIM when compared with HLT cows (Table 5). The predicted probabilities (LSM and SEM bars) for reproductive and survival outcomes by health group are presented in Figures 3 and 4.

\section{Effect of $\triangle B C S$ and Health Group on Milk Yield and Survival}

The main effects of $\triangle \mathrm{BCS}$ and health group were associated with M90 $(P<0.0001)$. The covariates that remained in the M90 model were geographical region $(P=0.1)$, parity $(P<0.0001)$, and season of calving $(P<0.001)$. Overall, M90 was greater in EL $(39.5 \pm$ $1.13 \mathrm{~kg} / \mathrm{d})$ and $\mathrm{ML}(38.9 \pm 1.11 \mathrm{~kg} / \mathrm{d})$ cows than in NC $(37.8 \pm 1.12 \mathrm{~kg} / \mathrm{d})$ and $\mathrm{GN}(36.2 \pm 1.12 \mathrm{~kg} / \mathrm{d})$ cows. On the other hand, M90 was lower in REP $(37.0 \pm 1.11$ $\mathrm{kg} / \mathrm{d})$ cows compared with OTH $(38.7 \pm 1.12 \mathrm{~kg} / \mathrm{d})$ and HLT cows $(38.6 \pm 1.11 \mathrm{~kg} / \mathrm{d}$; Figure 5$)$.

The main effects of $\triangle \mathrm{BCS}(P=0.04)$ and the health group $(P=0.02)$ were statistically associated with $\mathrm{CD}$. Cows with ML had greater odds of CD compared with cows with EL $(1.26 ; 1.02-1.56 ; P=0.02)$, cows diagnosed with REP or OTH disorder had greater odds of CD compared with HLT cows $(\mathrm{OR}=1.28 ; 1.08-1.50$; $P=0.001$ and $\mathrm{OR}=1.23 ; 1.09-1.54 ; P=0.001)$. The interaction term $\triangle \mathrm{BCS}$ by health group was not statistically significant $(P=0.43)$.

\section{DISCUSSION}

This study explored the complex associations between measurable changes in body condition, disease occurrences, and reproductive performance, milk yield, and survival. Analyses included responses that are accessible in modern dairy farms and could facilitate more informed decisions regarding management or culling.

Contrary to the hypothesis of this study, the effect of the interaction term $\triangle \mathrm{BCS}$ by health group was not statistically significant for any of the study outcomes. These associations were tested by building logistic models with interaction terms and application of different contrasts. A limitation of the current study, where BCS was evaluated at 2 specific points, is our inability to determine a more extensive temporal relationship between the changes in BCS and occurrence of disease.
It is also possible that cows excluded due to no BCS at $40 \pm 3$ DIM may have been most severely affected by disease and loss of BC.

As presented in Figure 1, independent associations of $\triangle \mathrm{BCS}$ and health group with the proposed outcomes can be tested as main effects. Additionally, potential interactions between $\triangle \mathrm{BCS}$ and health events within 40 DIM are plausible but were determined not statistically significant. In addition, the resulting $P$-values from the chi-squared test for the independency between these 2 variables were not statistically significant.

In agreement with our overall results, the effects of loss of BCS and suboptimal health during early lactation on fertility, milk yield, and survival have been documented (Hernandez et al., 2012; Carvalho et al., 2019; Pinedo et al., 2020b). Carvalho et al. (2014) determined that pregnancy per AI was affected con-

Table 4. Adjusted odds ratios (OR) for resumption of ovarian cyclicity, pregnancy at first AI, pregnancy loss, pregnancy at 150 DIM and at 305 DIM, and live culling or death after 40 DIM by category of change in BCS $(\triangle \mathrm{BCS})$ during the first $40 \mathrm{DIM}$; the population included 11,729 cows located in 16 herds in 4 regions in the United States

\begin{tabular}{|c|c|c|}
\hline$\Delta \mathrm{BCS}$ category $(\mathrm{n})^{1}$ & OR $(95 \% \mathrm{CI})$ & $P$-value \\
\hline \multicolumn{3}{|c|}{$\overline{\text { Resumption of ovarian cyclicity }^{2}}$} \\
\hline Gained & $1.94(1.57-2.40)$ & $<0.0001$ \\
\hline No change & $1.59(1.28-1.97)$ & $<0.0001$ \\
\hline Moderate loss & $1.27(1.10-1.47)$ & 0.0002 \\
\hline \multirow{2}{*}{\multicolumn{3}{|c|}{ Pregnancy at first $\mathrm{AI}^{3}$}} \\
\hline & & \\
\hline Gained & $0.93(0.74-1.16)$ & 0.82 \\
\hline No change & $0.93(083-1.12)$ & 0.97 \\
\hline Moderate loss & $0.97(0.83-1.14)$ & 0.79 \\
\hline Excessive loss & Referent & \\
\hline \multicolumn{3}{|l|}{ Pregnancy loss ${ }^{4}$} \\
\hline Gained & $1.41(0.92-2.16)$ & 0.16 \\
\hline No change & $1.18(0.86-1.62)$ & 0.54 \\
\hline Moderate loss & $1.15(0.85-1.55)$ & 0.63 \\
\hline Excessive loss & Referent & \\
\hline \multicolumn{3}{|l|}{ Pregnancy at 150 DIM } \\
\hline Gained & $1.61(1.20-2.17)$ & $<0.0001$ \\
\hline No change & $1.23(0.95-1.59)$ & 0.15 \\
\hline Moderate loss & $1.19(0.92-1.51)$ & 0.28 \\
\hline Excessive loss & Referent & \\
\hline \multicolumn{3}{|l|}{ Pregnancy at 305 DIM } \\
\hline Gained & $1.01(0.72-1.44)$ & 0.99 \\
\hline No change & $0.9(0.59-1.38)$ & 0.92 \\
\hline Moderate loss & $0.99(0.65-1.50)$ & 0.99 \\
\hline Excessive loss & Referent & \\
\hline \multicolumn{3}{|l|}{ Live culling or death } \\
\hline Gained & $0.93(0.68-1.29)$ & 0.95 \\
\hline No change & $1.06(0.79-1.41)$ & 0.95 \\
\hline Moderate loss & $1.26(1.02-1.56)$ & 0.02 \\
\hline Excessive loss & Referent & \\
\hline
\end{tabular}

${ }^{1}$ Excessive loss of BCS: $\triangle \mathrm{BCS} \leq-0.75$ (reference category, Ref); moderate loss of BCS: $\triangle \mathrm{BCS}=-0.5$ to -0.25 ; no change of BCS: $\triangle \mathrm{BCS}$ $=0$; gained BCS: $\triangle \mathrm{BCS} \geq 0.25$.

${ }^{2}$ Resumption of ovarian cyclicity assessed at $40 \pm 3$ and $54 \pm 3$ DIM. ${ }^{3}$ Pregnancy after the first AI assessed at $32 \pm 3 \mathrm{~d}$ after AI and reconfirmed at $60 \pm 3 \mathrm{~d}$ of gestation.

${ }^{4}$ Pregnancy loss assessed at $60 \pm 3 \mathrm{~d}$ of gestation; this category included cows pregnant after the first and second AI. 


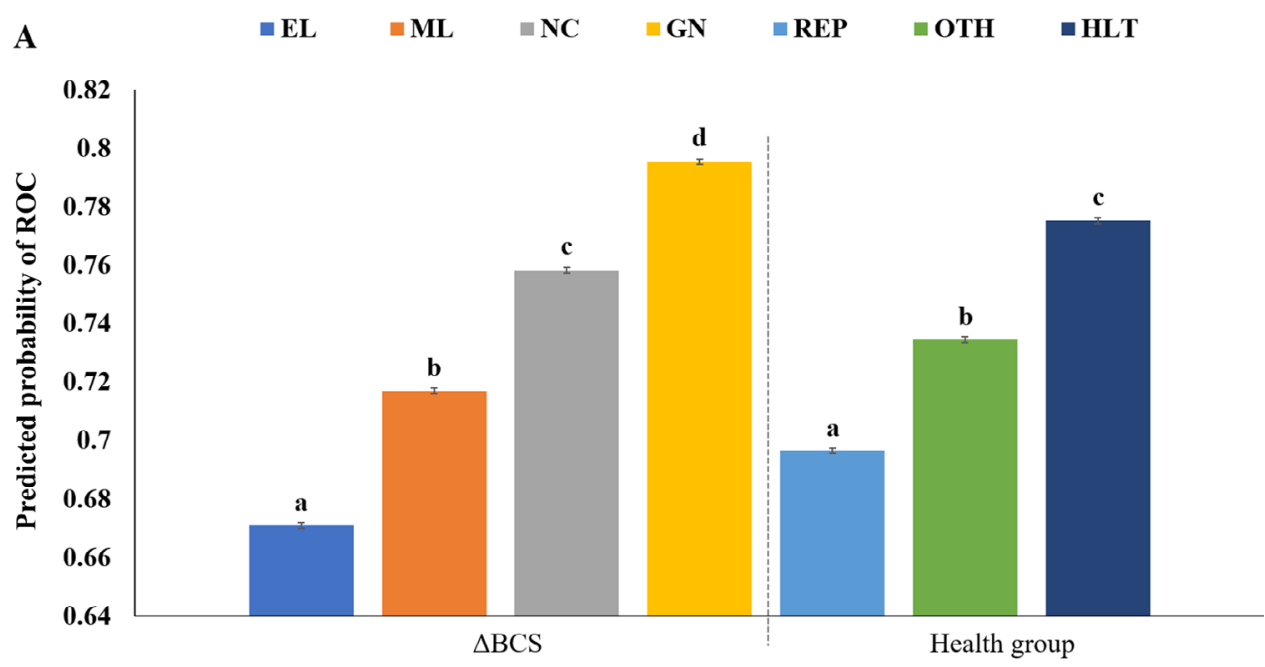

B

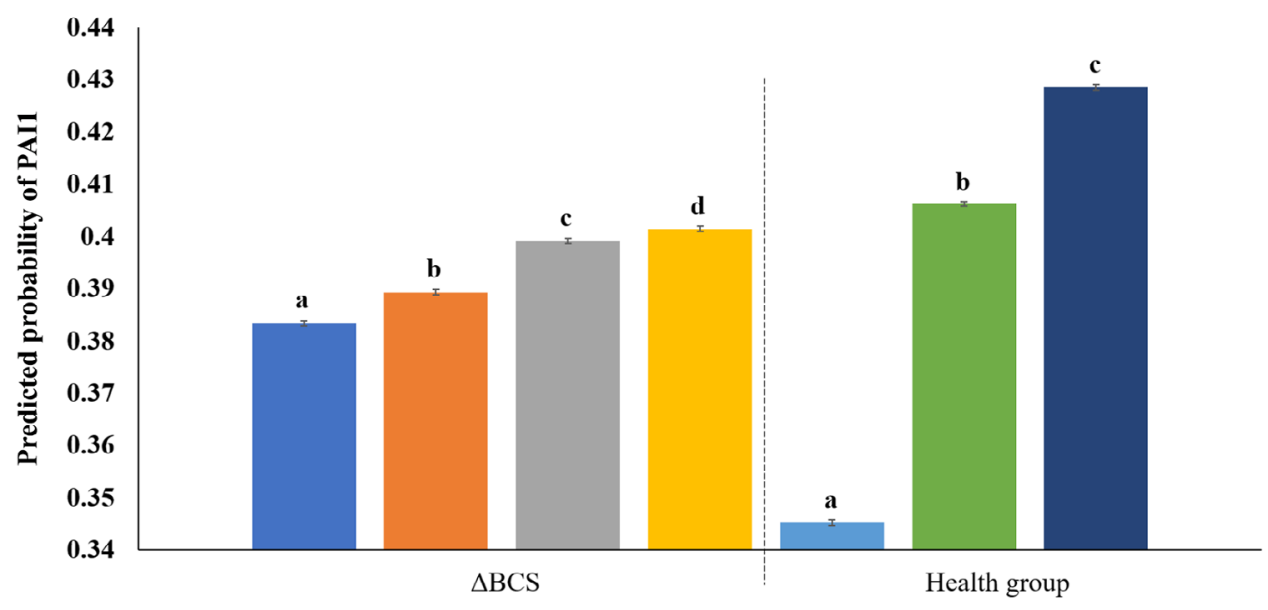

C

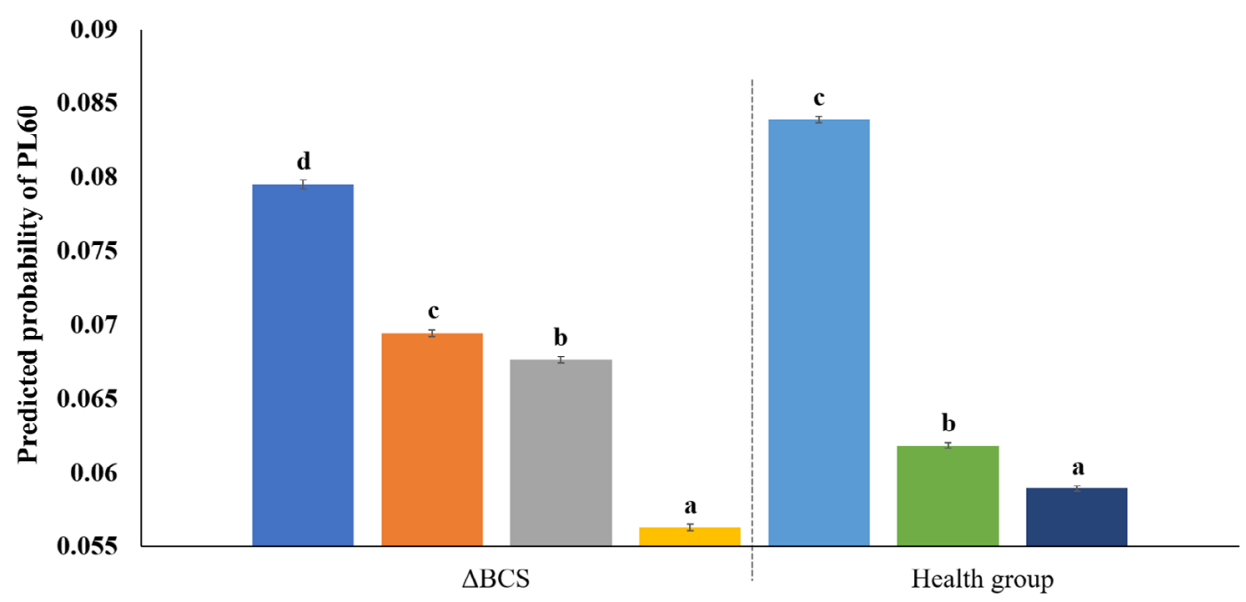

Figure 3. (A) Predicted probabilities (LSM and 95\% CI bars) for resumption of ovarian cyclicity (ROC), (B) pregnancy at first AI (PAI1), and (C) pregnancy loss (PL60) presented by BCS change category and by health group. The population included 11,729 cows located in 16 herds in 4 regions in the United States. Resumption of ovarian cyclicity assessed at $40 \pm 3$ and $54 \pm 3$ DIM; pregnancy at first AI assessed at $32 \pm 3$ $\mathrm{d}$ after $\mathrm{AI}$ and reconfirmed at $60 \pm 3 \mathrm{~d}$ of gestation; and pregnancy loss assessed at $60 \pm 3 \mathrm{~d}$ of gestation. EL $=$ excessive loss of BCS ( $\Delta \mathrm{BCS}$ $\leq-0.75) ; \mathrm{ML}=$ moderate loss of $\mathrm{BCS}(\Delta \mathrm{BCS}=-0.5$ to -0.25$) ; \mathrm{NC}=$ no change of $\mathrm{BCS}(\Delta \mathrm{BCS}=0) ; \mathrm{GN}=$ gained $\mathrm{BCS}(\Delta \mathrm{BCS} \geq 0.25)$. Health-related events within 40 DIM: REP = reproductive-related events (dystocia, twins, retained fetal membranes, metritis, and clinical endometritis); OTH = other health-related events (subclinical ketosis, displaced abomasum, lameness, clinical mastitis, respiratory disease). HLT $=$ cows not diagnosed with REP or OTH events. Different letters indicate statistical significance at $P$-values $<0.05$. 


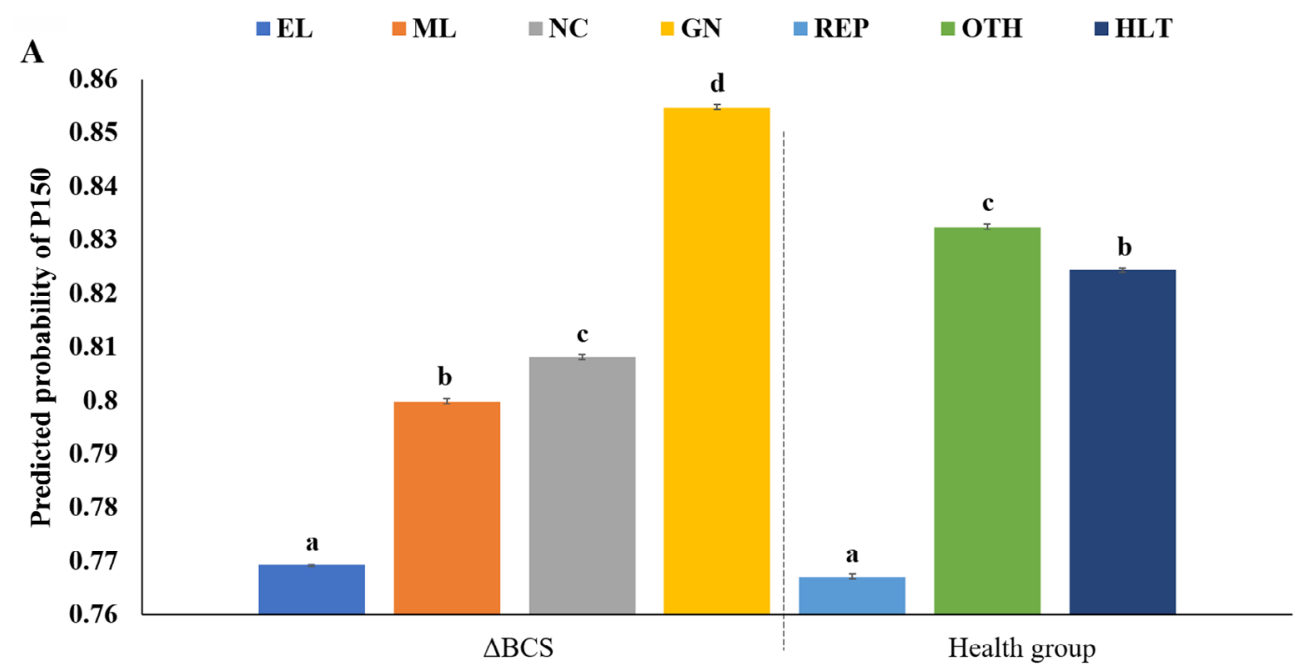

B

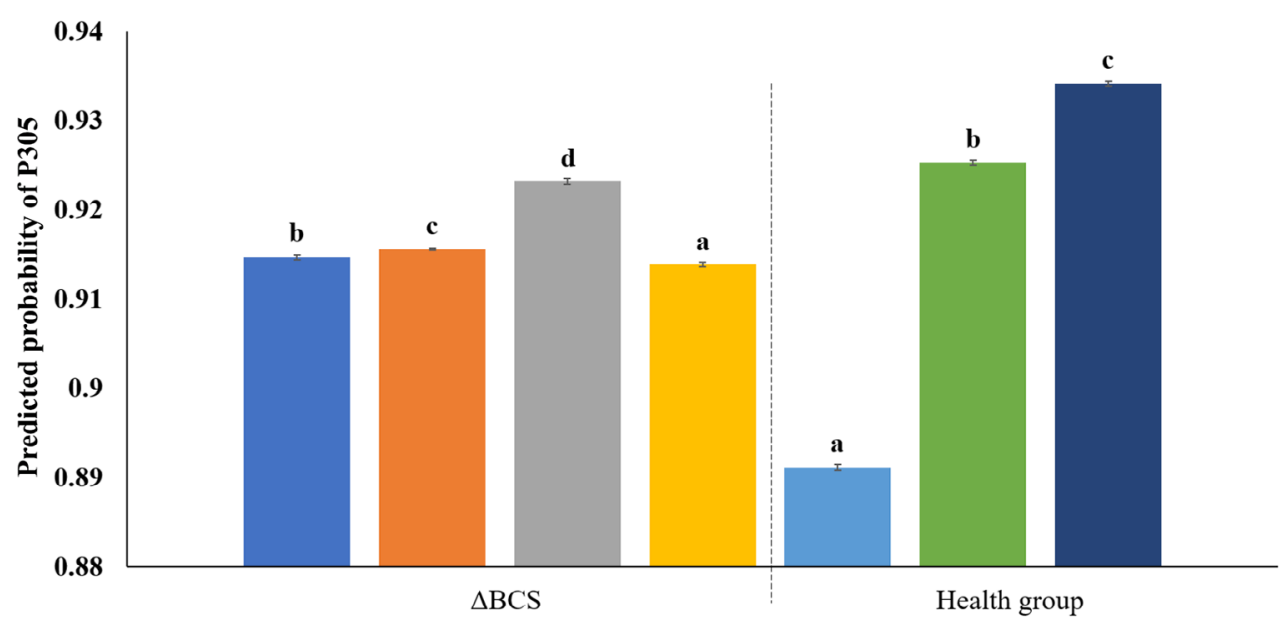

C

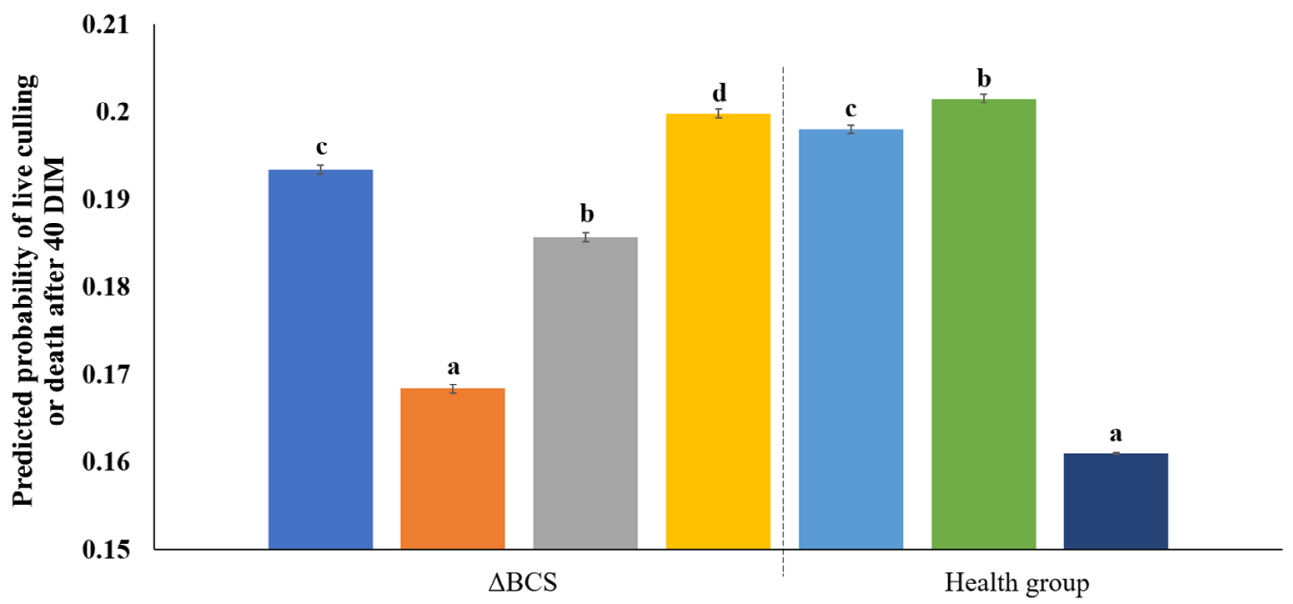

Figure 4. Predicted probabilities (LSM and 95\% CI bars) for pregnancy (A) at 150 DIM (P150) and (B) at 305 DIM (P305), and (C) live culling or death after 40 DIM presented by BCS change category and by health group. The population included 11,729 cows located in 16 herds in 4 regions in the United States. $\mathrm{EL}=$ excessive loss of BCS $(\triangle \mathrm{BCS} \leq-0.75)$; $\mathrm{ML}=$ moderate loss of $\mathrm{BCS}(\Delta \mathrm{BCS}=-0.5$ to -0.25$)$; $\mathrm{NC}=$ no change of BCS $(\triangle \mathrm{BCS}=0)$; GN $=$ gained BCS $(\triangle \mathrm{BCS} \geq 0.25)$. Health-related events within $\leq 40$ DIM: REP $=$ reproductive-related events (dystocia, twins, retained fetal membranes, metritis, and clinical endometritis); OTH = other health-related events (subclinical ketosis, displaced abomasum, lameness, clinical mastitis, respiratory disease). HLT $=$ cows not diagnosed with REP or OTH events. Different letters indicate statistical significance at $P$-values $<0.05$. 
siderably by BCS change from calving until the third week postpartum and most reduced for cows that lost BCS $(22.8 \%)$, intermediate for cows that maintained BCS (36.0\%), and greatest for cows that gained BCS (78.3\%). Similarly, Chebel et al. (2018) demonstrated that loss of BCS during the dry period was associated with reduced likelihood of pregnancy after the first and second postpartum inseminations. Additionally, loss of BCS after calving increased the risk of uterine disease, digestive disorders, and use of anti-inflammatory or antimicrobials within the first 60 DIM.

The negative effect of compromised health in postpartum dairy cows also is also recognized widely. The occurrence of uterine, metabolic, and other health disorders has been identified extensively as a risk factor for lower subsequent fertility, milk yield and higher risk of culling (Santos et al., 2010; Ribeiro et al., 2013; Carvalho et al., 2019; Mohtashamipour et al., 2020; Pinedo et al., 2020b).

Research on the combined effects of occurrences of reproductive disorders combined with categories of $\triangle \mathrm{BCS}$ on fertility responses, milk yield, and survival is scarce. The proposed hypothesis on the variation in the effect of $\triangle \mathrm{BCS}$ on the study outcomes within different health groups was based on the biological relationship between BCS, NEB, and disease (Kalilani and Atashili, 2006; Roche et al., 2009; Stevenson et al., 2020). However, as in our study the statistical interaction between $\triangle \mathrm{BCS}$ and disease was not statistically significant, results do not support the idea of a potential association (de Mutsert et al., 2009).

Although adding health information to data on $\triangle \mathrm{BCS}$ seems logical from a physiological point of view, this approach has not been widely explored to support management decisions. The carryover effect of loss of body condition, as an indirect measure of energy balance in early lactation, and health, as a measure of metabolic, immune, and homeostatic functions, on a delayed ROC postpartum has been documented (Nebel and McGillard, 1993; Beever, 2006; Stevenson et al., 2020). Specific factors affecting proper resumption of cyclicity include parity (Zhang et al., 2010), alteration in recoupling the growth hormone-IGF-1 axis in the liver (Santos et al., 2016), metabolic and infectious disorders (Santos et al., 2009; Pinedo et al., 2020b), insufficient concentrations of progesterone (Wiltbank et al., 2008), dystocia, NEB, and body condition loss (Wiltbank et al., 2002; Walsh et al., 2007; Ribeiro et al., 2013). These implications may explain the effects of level of body condition change and disease on variables such as ROC (Tables 4 and 5), which supports the idea of using information from BCS and health for prediction of fertility.
In this study, pregnancy loss was assessed at $60 \mathrm{~d}$ after AI, following an initial pregnancy diagnosis at $32 \mathrm{~d}$ after AI. The losses during this period represent about $12 \%$ of the pregnancy losses in high producing cows (Wiltbank et al., 2016), which has been reported to be of substantial importance in determining the reproductive efficiency of dairy herds (Chebel et al., 2004; Inskeep and Dailey, 2005). Abnormal placentation, alteration in the vascularization of placenta, and embryonic/fetal development defects commonly occur during this period (Wiltbank et al., 2016). Additionally, risk factors such as anovulation at the end of the voluntary waiting period (Santos et al. 2004), parity (Santos et al., 2009), uterine diseases (Ribeiro et al., 2013), mastitis (Dahl et al., 2017), and severe $\triangle$ BCS (Santos et al., 2009; Chebel et al., 2018) have been associated with pregnancy loss at $60 \mathrm{~d}$ of gestation. Therefore, greater pregnancy loss in cows that lost BCS or were sick was expected.

Table 5. Adjusted odds ratios (OR) for resumption of ovarian cyclicity, pregnancy at first AI, pregnancy loss, pregnancy at 150 DIM and at 305 DIM, and live culling or death after 40 DIM by health group during the first 40 DIM; the population included 11,729 cows located in 16 herds in 4 regions in the United States

\begin{tabular}{|c|c|c|}
\hline Health group $(\mathrm{n})^{1}$ & OR $(95 \% \mathrm{CI})$ & $P$-value \\
\hline \multicolumn{3}{|c|}{ Resumption of ovarian cyclicity ${ }^{2}$} \\
\hline $\operatorname{REP}(5,418)$ & $0.65(0.56-0.76)$ & $<0.0001$ \\
\hline OTH $(1,873)$ & $0.79(0.68-0.92)$ & 0.0007 \\
\hline HLT $(3,809)$ & Referent & \\
\hline \multicolumn{3}{|c|}{ Pregnancy at first $\mathrm{AI}^{3}$} \\
\hline REP & $0.70(0.58-0.84)$ & $<0.0001$ \\
\hline OTH & $0.91(0.76-1.08)$ & 0.41 \\
\hline \multirow{2}{*}{\multicolumn{3}{|c|}{ Pregnancy loss ${ }^{4}$}} \\
\hline & & \\
\hline REP & $1.45(1.08-1.95)$ & 0.009 \\
\hline OTH & $1.06(0.79-1.41)$ & 0.89 \\
\hline HLT & Referent & \\
\hline \multicolumn{3}{|c|}{ Pregnancy at 150 DIM } \\
\hline REP & $0.73(0.59-0.87)$ & $<0.0001$ \\
\hline $\mathrm{OTH}$ & $1.06(0.89-1.263)$ & 0.74 \\
\hline HLT & Referent & \\
\hline \multicolumn{3}{|c|}{ Pregnancy at 305 DIM } \\
\hline REP & $0.58(0.49-0.69)$ & $<0.0001$ \\
\hline $\mathrm{OTH}$ & $0.69(0.66-1.15)$ & 0.48 \\
\hline HLT & Referent & \\
\hline \multicolumn{3}{|c|}{ Live culling or death } \\
\hline REP & $1.28(1.08-1.50)$ & $<0.0001$ \\
\hline OTH & $1.23(1.09-1.54)$ & 0.48 \\
\hline HLT & Referent & \\
\hline
\end{tabular}

${ }^{1}$ Health group: $\mathrm{REP}=$ reproductive-related events (dystocia, twins, retained fetal membranes, metritis, and clinical endometritis); OTH $=$ other health events (subclinical ketosis, displaced abomasum, lameness, clinical mastitis, respiratory disease); HLT $=$ cows not diagnosed with REP or OTH events.

${ }^{2}$ Resumption of ovarian cyclicity assessed at $40 \pm 3$ and $54 \pm 3$ DIM. ${ }^{3}$ Pregnancy after the first AI assessed at $32 \pm 3 \mathrm{~d}$ after AI and reconfirmed at $60 \pm 3 \mathrm{~d}$ of gestation.

${ }^{4}$ Pregnancy loss assessed at $60 \pm 3 \mathrm{~d}$ of gestation; this category included cows pregnant after the first and second AI. 


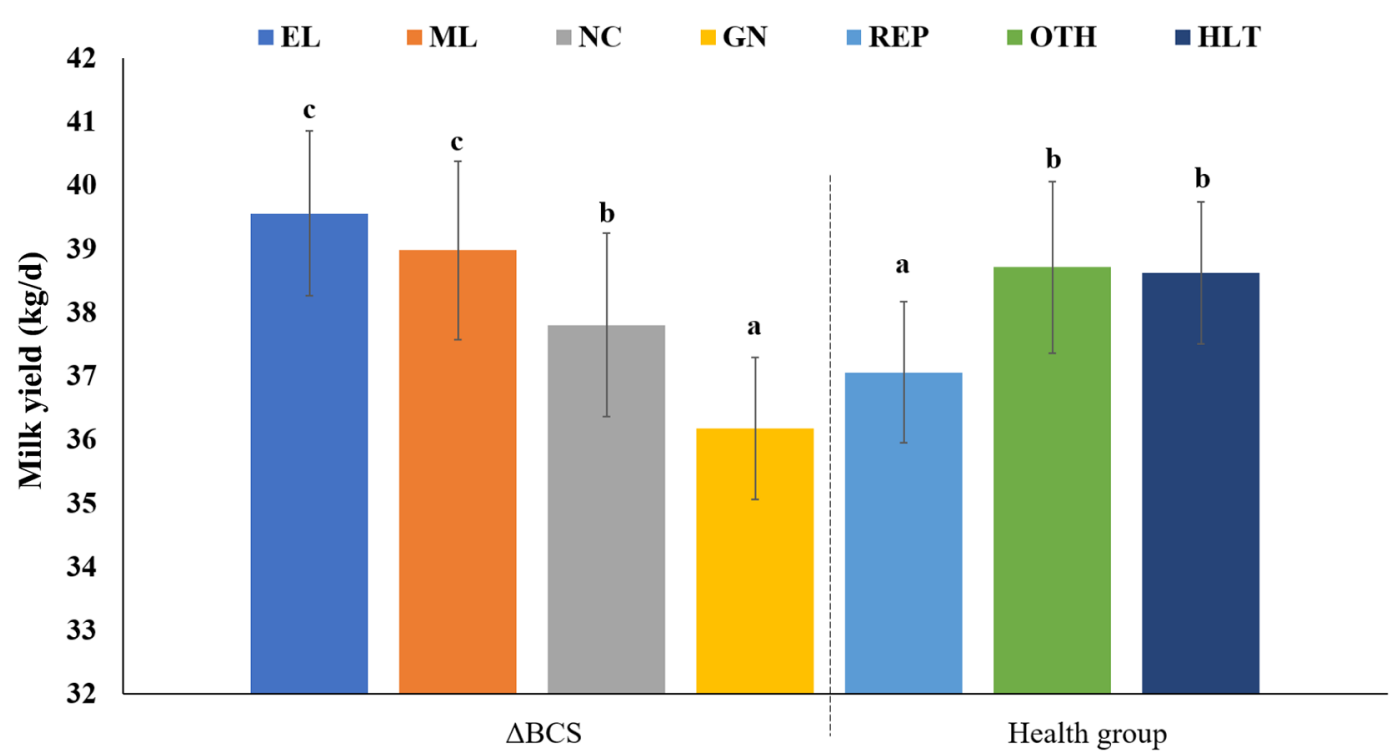

Figure 5. Average daily milk yield (LSM and 95\% CI bars) in the first 90 DIM (kg/d) presented by body condition score change category and by health group. The population included 11,729 cows located in 16 herds in 4 regions in the United States. EL = excessive loss of BCS $(\Delta \mathrm{BCS} \leq-0.75) ; \mathrm{ML}=$ moderate loss of $\mathrm{BCS}(\Delta \mathrm{BCS}=-0.5$ to -0.25$) ; \mathrm{NC}=$ no change of $\mathrm{BCS}(\Delta \mathrm{BCS}=0) ; \mathrm{GN}=$ gained $\mathrm{BCS}(\Delta \mathrm{BCS}$ $\geq 0.25$ ). Health-related events within 40 DIM: REP = reproductive-related events (dystocia, twins, retained fetal membranes, metritis, and clinical endometritis); OTH = other health-related events (subclinical ketosis, displaced abomasum, lameness, clinical mastitis, respiratory disease). HLT $=$ cows not diagnosed with REP or OTH events. Different letters indicate statistical significance at $P$-values $<0.05$. Model covariates: geographical region $(P=0.1)$, parity $(P<0.0001)$, and season of calving $(P<0.001)$.

Associations between pregnancy and pregnancy loss at mid- or late lactation with predictors that occurred at early lactation may be difficult to measure due to the distance between the time of exposure and the outcomes. Additionally, unmeasured variables may affect the ability to detect associations in observational studies. Nonetheless, some authors have proven strong associations between $\triangle \mathrm{BCS}$ during dry period and BCS around insemination on likelihood of pregnancy after subsequent postpartum inseminations (Hernandez et al., 2012; Chebel et al., 2018; Stevenson et al., 2020). Chebel et al., (2018) showed smaller odds of P150 in cows with EL, ML, and NC at 40 DIM compared with GB cows. In agreement with these reports, as illustrated in Figures 3 and 4, in this study the probabilities of success for reproductive outcomes differed by $\triangle$ BCS. Similarly, differences were also determined among health statuses, especially for REP cows.

Outcomes P305 and CD are long-term responses relative to the health and BCS assessments performed in this study during early lactation. The negative longterm effects of health disorders during early lactation on reproductive performance at 150 DIM, pregnancy at 305 DIM, milk yield, and culling have been reported (Carvalho et al., 2019). Thus, transition diseases seem to compromise cow physiology and performance, even after clinical recovery from health problems, which can significantly contribute to the overall effect of clinical diseases (Ribeiro et al., 2016). However, the mechanisms of the carryover effects of postpartum diseases on long-term responses are not fully described (Carvalho et al., 2019). Nonetheless, we observed different probabilities of leaving the herd after 40 DIM within health groups (Figure 4).

Subsequent average 305 milk yield $(\mathrm{kg} / \mathrm{d})$ has been associated with the $\triangle \mathrm{BCS}$ observed during the dry period. Chebel et al. (2018) indicated that cows that gained BCS had greater milk yield compared with cows with EL and ML. Conversely, in our study, $\triangle B C S$ EL cows had consistently the greatest milk yield during the first 90 DIM (Figure 5), which reflects the need for nutrient resources in high producing cows. Disease also played a significant role in milk yield. Cows in REP had the lowest milk yield compared with OTH and HLT cows (Figure 5). This would also suggest that genetic merit for high milk yield favors NEB, as indicated by EL (Buckley et al., 2000) and, under this metabolic environment, REP disorders significantly reduce milk yield.

Because most diseases depend on the combined action of multiple factors, such as physiological pathways in the host, presence of pathogens, genetic makeup, and environment, the identification of combined effects as potential predictors for impaired reproduction and decreased productivity of cows can be of interest to improve dairy herds' management and profitability 
(Bicalho et al., 2017; Probo et al., 2018). The present study included multiple herds in 4 geographical regions in the United States, where cows were exposed to variable prepartum and postpartum management and environmental conditions. Nevertheless, the changes that we have identified in response to loss in BCS and health-related events imply uniformity of targets to consider for improvement of nutritional, health, and reproductive management of dairy cows.

\section{CONCLUSIONS}

Both $\triangle \mathrm{BCS}$ and health status measured within 40 DIM influenced subsequent cow performance and survival. Contrary to the hypothesis presented, the effect of the interaction term $\triangle \mathrm{BCS}$ by health group was not statistically significant for any of the outcomes. In general terms, excessive loss of BCS and reproductive diseases decreased reproductive performance and survival compared with other $\triangle \mathrm{BCS}$ categories and health groups. Furthermore, excessive loss of BCS during early postpartum (40 DIM) was characterized as having higher milk yield. The magnitude of the changes in BCS and health statuses of early lactation cows should be considered when assessing subsequent performance and survival.

\section{ACKNOWLEDGMENTS}

The authors acknowledge USDA (NIFA AFRI Translational Genomics for Improved Fertility of Animals grant no. 2013-68004; Washington, DC) for financial support to perform the phenotyping of the study animals. The authors thank the participant dairy farms that allowed the weekly monitoring of cows. The authors have not stated any conflicts of interest.

\section{REFERENCES}

Bach, A., M. Dinarés, M. Devant, and X. Carré. 2007. Associations between lameness and production, feeding and milking attendance of Holstein cows milked with an automatic milking system. J. Dairy Res. 74:40-46. https://doi.org/10.1017/S0022029906002184.

Barletta, R. V., M. Maturana Filho, P. D. Carvalho, T. A. Del Valle, A. S. Netto, F. P. Rennó, R. D. Mingoti, J. R. Gandra, G. B. Mourão, P. M. Fricke, R. Sartori, E. H. Madureira, and M. C. Wiltbank. 2017. Association of changes among body condition score during the transition period with NEFA and BHBA concentrations, milk production, fertility, and health of Holstein cows. Theriogenology 104:30-36. https://doi.org/10.1016/j.theriogenology.2017.07.030.

Bauman, D. E., and W. B. Currie. 1980. Partitioning of nutrients during pregnancy and lactation: A review of mechanisms involving homeostasis and homeorhesis. J. Dairy Sci. 63:1514-1529. https:// doi.org/10.3168/jds.S0022-0302(80)83111-0.

Beever, D. E. 2006. The impact of controlled nutrition during the dry period on dairy cow health, fertility and performance. Anim. Reprod. Sci. 96:212-226. https://doi.org/10.1016/j.anireprosci.2006 .08 .002 .
Beltman, M. E., J. C. McNally, E. Kelly, and M. A. Crowe. 2020. Relationship between plasma concentrations of IGF-I and clinical endometritis, and response to progesterone synchrony in dairy cows during early lactation. J. Dairy Sci. 103:9493-9501. https:// doi.org/10.3168/jds.2019-17974.

Bicalho, M. L. S., E. C. Marques, R. O. Gilbert, and R. C. Bicalho. 2017. The association of plasma glucose, BHBA, and NEFA with postpartum uterine diseases, fertility, and milk production of Holstein dairy cows. Theriogenology 88:270-282. https://doi.org/10 .1016/j.theriogenology.2016.09.036.

Bicalho, R. C., S. H. Cheong, G. Cramer, and C. L. Guard. 2007. Association between a visual and an automated locomotion score in lactating Holstein cows. J. Dairy Sci. 90:3294-3300. https://doi .org/10.3168/jds.2007-0076.

Bicalho, R. C., K. N. Galvão, C. L. Guard, and J. E. P. Santos. 2008 Optimizing the accuracy of detecting a functional corpus luteum in dairy cows. Theriogenology 70:199-207. https://doi.org/10 .1016/j.theriogenology.2008.03.015.

Buckley, F., P. Dillon, S. Crosse, F. Flynn, and M. Rath. 2000. The performance of Holstein Friesian dairy cows of high and medium genetic merit for milk production on grass-based feeding systems. Livest. Prod. Sci. 64:107-119. https://doi.org/10.1016/S0301 -6226(99)00167-0.

Carvalho, M. R., F. Penagaricano, J. E. P. Santos, T. J. DeVries, B. W. McBride, and E. S. Ribeiro. 2019. Long-term effects of postpartum clinical disease on milk production, reproduction, and culling of dairy cows. J. Dairy Sci. 102:11701-11717. https://doi .org/10.3168/jds.2019-17025.

Carvalho, P. D., A. H. Souza, M. C. Amundson, K. S. Hackbart, M. J. Fuenzalida, M. M. Herlihy, H. Ayres, A. R. Dresch, L. M. Vieira, J. N. Guenther, R. R. Grummer, P. M. Fricke, R. D. Shaver, and M. C. Wiltbank. 2014. Relationships between fertility and postpartum changes in body condition and body weight in lactating dairy cows. J. Dairy Sci. 97:3666-3683. https://doi.org/10.3168/ jds.2013-7809.

Cerri, R. L. A., J. E. P. Santos, S. O. Juchem, K. N. Galvao, and R. C. Chebel. 2004. Timed artificial insemination with estradiol cypionate or insemination at estrus in high-producing dairy cows. J. Dairy Sci. 87:3704-3715. https://doi.org/10.3168/jds.S0022 -0302(04)73509-2.

Chebel, R. C., L. G. D. Mendonça, and P. S. Baruselli. 2018. Association between body condition score change during the dry period and postpartum health and performance. J. Dairy Sci. 101:45954614. https://doi.org/10.3168/jds.2017-13732.

Chebel, R. C.. J. E. P. Santos, J. P. Reynolds, R. L. A. Cerri, S. O. Juchem, and M. Overton. 2004. Factors affecting conception rate after artificial insemination and pregnancy loss in lactating dairy cows. Anim. Reprod. Sci. 84:239-255. https://doi.org/10.1016/j .anireprosci.2003.12.012.

Dahl, M. O., F. P. Maunsell, A. De Vries, K. N. Galvao, C. A. Risco, and J. A. Hernandez. 2017. Evidence that mastitis can cause pregnancy loss in dairy cows: A systematic review of observational studies. J. Dairy Sci. 100:8322-8329. https://doi.org/10.3168/jds 2017-12711.

Daros, R. R., C. D. Havekes, and T. J. DeVries. 2021. Body condition loss during the dry period: Insights from feeding behavior studies. J. Dairy Sci. 104:4682-4691. https://doi.org/10.3168/jds.2020 $-19481$.

de Mutsert, R., K. J. Jager, C. Zoccali, and F. W. Dekker. 2009. The effect of joint exposures: Examining the presence of interaction. Kidney Int. 75:677-681. https://doi.org/10.1038/ki.2008.645.

Dohoo, I., W. Martin, and H. Stryhn. 2009. Veterinary Epidemiologic Research. 2nd ed. AVC Inc.

Ferguson, J. D., D. T. Galligan, and N. Thomsen. 1994. Principal descriptors of body condition score in Holstein cows. J. Dairy Sci. 77:2695-2703. https://doi.org/10.3168/jds.S0022-0302(94)77212 $-\mathrm{X}$.

Folnožić, I., M. Sarnardžija, D. Đurčić, S. Vince, S. Perkov, S. Jelušić, H. Valpotić, B. B. Ljubić, M. Lojkić, D. Gračner, I. Ż. Žaja, N Maćešić, J. Grizelj, T. Dobranić, G. Redžepi, Z. Šostar, and R. Turk. 2019. Effects of in-feed clinoptilolite treatment on serum 
metabolic and antioxidative biomarkers and acute phase response in dairy cows during pregnancy and early lactation. Res. Vet. Sci. 127:57-64. https://doi.org/10.1016/j.rvsc.2019.10.010.

Gärtner, T., E. Gernand, J. Gottschalk, and K. Donat. 2019. Relationships between body condition, body condition loss, and serum metabolites during the transition period in primiparous and multiparous cows. J. Dairy Sci. 102:9187-9199. https://doi.org/10 $.3168 /$ jds.2018-15762.

Gross, J., H. A. van Dorland, R. M. Bruckmaier, and F. J. Schwarz. 2011. Performance and metabolic profile of dairy cows during a lactational and deliberately induced negative energy balance with subsequent realimentation. J. Dairy Sci. 94:1820-1830. https://doi .org/10.3168/jds.2010-3707.

Hernandez, J. A., C. A. Risco, F. S. Lima, and J. E. Santos. 2012. Observed and expected combined effects of clinical mastitis and low body condition on pregnancy loss in dairy cows. Theriogenology 77:115-121. https://doi.org/10.1016/j.theriogenology.2011.07.023.

Inskeep, E. K., and R. A. Dailey. 2005. Embryonic death in cattle. Vet. Clin. North Am. Food Anim. Pract. 21:437-461. https://doi.org/ 10.1016/j.cvfa.2005.02.002.

Kalilani, L., and J. Atashili. 2006. Measuring additive interaction using odds ratios. Epidemiol. Perspect. Innov. 3:5. https://doi.org/ 10.1186/1742-5573-3-5.

Kasimanickam, R. K., V. R. Kasimanickam, J. R. Olsen, E. J. Jeffress, D. A. Moore, and J. P. Kastelic. 2013. Associations among serum pro- and anti-inflammatory cytokines, metabolic mediators, body condition, and uterine disease in postpartum dairy cows. Reprod. Biol. Endocrinol. 11:103. https://doi.org/10.1186/1477-7827-11 $-103$.

Kvidera, S. K., E. A. Horst, M. Abuajamieh, E. J. Mayorga, M. V. Sanz Fernandez, and L. H. Baumgard. 2017. Glucose requirements of an activated immune system in lactating Holstein cows. J. Dairy Sci. 100:2360-2374. https://doi.org/10.3168/jds.2016-12001.

Lang, C. H., and C. Dobrescu. 1991. Sepsis-induced increases in glucose uptake by macrophage-rich tissues persist during hypoglycemia. Metabolism 40:585-593. https://doi.org/10.1016/0026 -0495(91)90048-2.

Lean, I. J., R. Van Saun, and P. J. DeGaris. 2013. Energy and protein nutrition management of transition dairy cows. Vet. Clin. North Am. Food Anim. Pract. 29:337-366. https://doi.org/10.1016/j .cvfa.2013.03.005.

Lochmiller, R., and C. Deerenberg. 2000. Trade-offs in evolutionary immunology: Just what is the cost of immunity? Oikos 88:87-98. https://doi.org/10.1034/j.1600-0706.2000.880110.x.

Lopes, F., G. Rosa, P. Pinedo, J. E. P. Santos, R. C. Chebel, K. N. Galvao, G. M. Schuenemann, R. C. Bicalho, R. O. Gilbert, S. Rodrigez-Zas, C. M. Seabury, and W. Thatcher. 2020. Genomeenable prediction for health traits using high-density SNP panel in US Holstein cattle. Anim. Genet. 51:192-199. https://doi.org/ 10.1111/age.12892.

McDougall, S., R. Macaulay, and C. Compton. 2007. Association between endometritis diagnosis using a novel intravaginal device and reproductive performance in dairy cattle. Anim. Reprod. Sci. 99:9 23. https://doi.org/10.1016/j.anireprosci.2006.03.017.

Mee, J. F. 2008. Prevalence and risk factors for dystocia in dairy cattle: A review. Vet. J. 176:93-101. https://doi.org/10.1016/j.tvjl 2007.12.032.

Miguel-Pacheco, G. G., J. Kaler, J. Remnant, L. Cheyne, C. Abbott, A. P. French, T. P. Pridmore, and J. N. Huxley. 2014. Behavioural changes in dairy cows with lameness in an automatic milking system. Appl. Anim. Behav. Sci. 150:1-8. https://doi.org/10.1016/j .applanim.2013.11.003.

Mohtashamipour, F., E. Dirandeh, Z. Ansari-Pirsaraei, and M. G. Colazo. 2020. Postpartum health disorders in lactating dairy cows and its associations with reproductive responses and pregnancy status after first timed-AI. Theriogenology 141:98-104. https://doi .org/10.1016/j.theriogenology.2019.09.017.

Nebel, R. L., and M. L. McGilliard. 1993. Interactions of high milkyield and reproductive-performance in dairy-cows. J. Dairy Sci. 76:3257-3268. https://doi.org/10.3168/jds.S0022-0302(93)77662 -6 .
Overton, T. R., J. A. A. McArt, and D. V. Nydam. 2017. A 100year review: Metabolic health indicators and management of dairy cattle. J. Dairy Sci. 100:10398-10417. https://doi.org/10.3168/jds 2017-13054.

Pinedo, P., J. E. P. Santos, R. C. Chebel, K. N. Galvão, G. M. Schuenemann, R. C. Bicalho, R. O. Gilbert, S. Rodriguez Zas, C. M Sea-bury, G. Rosa, and W. W. Thatcher. 2020a. Early-lactation diseases and fertility in 2 seasons of calving across US dairy herds. J. Dairy Sci. 103:10560-10576. https://doi.org/10.3168/jds.2019 $-17951$.

Pinedo, P., J. E. P. Santos, R. C. Chebel, K. N. Galvao, G. M. Schuenemann, R. C. Bicalho, R. O. Gilbert, S. L. Rodriguez-Zas, C. M. Seabury, G. Rosa, and W. Thatcher. 2020b. Associations of reproductive indices with fertility outcomes, milk yield, and survival in Holstein cows. J. Dairy Sci. 103:6647-6660. https://doi.org/10 .3168/jds.2019-17867.

Probo, M., O. B. Pascottini, S. LeBlanc, G. Opsomer, and M. Hostens. 2018. Association between metabolic diseases and the culling risk of high-yielding dairy cows in a transition management facility using survival and decision tree analysis. J. Dairy Sci. 101:94199429. https://doi.org/10.3168/jds.2018-14422.

Ribeiro, E. S., G. Gomes, L. F. Greco, R. L. A. Cerri, A. Vieira-Neto, P. L. J. Monteiro Jr., F. S. Lima, R. S. Bisinotto, W. W. Thatcher, and J. E. P. Santos. 2016. Carryover effect of postpartum inflammatory diseases on developmental biology and fertility in lactating dairy cows. J. Dairy Sci. 99:2201-2220. https://doi.org/10.3168/ jds.2015-10337.

Ribeiro, E. S., F. S. Lima, L. F. Greco, R. S. Bisinotto, A. P. Monteiro, M. Favoreto, H. Ayres, R. S. Marsola, N. Martinez, W. W. Thatcher, and J. E. P. Santos. 2013. Prevalence of periparturient diseases and effects on fertility of seasonally calving grazing dairy cows supplemented with concentrates. J. Dairy Sci. 96:5682-5697. https://doi.org/10.3168/jds.2012-6335.

Roche, J. R., N. C. Friggens, J. K. Kay, M. W. Fisher, K. J. Stafford, and D. P. Berry. 2009. Invited review: Body condition score and its association with dairy cow productivity, health, and welfare. J. Dairy Sci. 92:5769-5801. https://doi.org/10.3168/jds.2009-2431.

Sander, A. K., M. Piechotta, G. Schlamberger, H. Bollwein, M. Kaske, A. Sipka, and H. J. Schuberth. 2011. Ex vivo phagocytic overall performance of neutrophilic granulocytes and the relation to plasma insulin-like growth factor-I concentrations in dairy cows during the transition period. J. Dairy Sci. 94:1762-1771. https:// doi.org/10.3168/jds.2010-3275.

Santos, J. E. P., R. S. Bisinotto, and E. S. Ribeiro. 2016. Mechanisms underlying reduced fertility in anovular dairy cows. Theriogenology 86:254-262. https://doi.org/10.1016/j.theriogenology.2016.04 .038 .

Santos, J. E. P., R. S. Bisinotto, E. S. Ribeiro, F. S. Lima, L. F. Greco, C. R. Staples, and W. W. Thatcher. 2010. Applying nutrition and physiology to improve reproduction in dairy cattle. Soc. Reprod. Fertil. Suppl. 67:387-403. https://doi.org/10.5661/RDR-VII-387.

Santos, J. E. P., H. M. Rutigliano, and M. F. Sá Filho. 2009. Risk factors for resumption of postpartum estrous cycles and embryonic survival in lactating dairy cows. Anim. Reprod. Sci. 110:207-221. https://doi.org/10.1016/j.anireprosci.2008.01.014.

Santos, J. E. P., W. W. Thatcher, R. C. Chebel, R. L. A. Cerri, and K. N. Galvao. 2004. The effect of embryonic death rates in cattle on the efficacy of estrus synchronization programs. Anim. Reprod. Sci. 82-83:513-535. https://doi.org/10.1016/j.anireprosci.2004.04 .015 .

Sheldon, I. M., G. S. Lewis, S. LeBlanc, and R. O. Gilbert. 2006 Defining postpartum uterine disease in cattle. Theriogenology 65:1516-1530. https://doi.org/10.1016/j.theriogenology.2005.08 .021 .

Stevenson, J. S., S. Banuelos, and L. G. D. Mendonça. 2020. Transition dairy cow health is associated with first postpartum ovulation risk, metabolic status, milk production, rumination, and physical activity. J. Dairy Sci. 103:9573-9586. https://doi.org/10.3168/jds .2020-18636.

Vieira-Neto, A., I. R. P. Lima, F. Lopes Jr., C. Lopera, R. Zimpel, L. D. R. Sinedino, K. C. Jeong, K. Galvão, W. W. Thatcher, C. 
D. Nelson, and J. E. P. Santos. 2017. Use of calcitriol to maintain postpartum blood calcium and improve immune function in dairy cows. J. Dairy Sci. 100:5805-5823. https://doi.org/10.3168/ jds.2016-12506.

Walsh, R. B., D. F. Kelton, T. F. Duffield, K. E. Leslie, J. S. Walton, and S. J. LeBlanc. 2007. Prevalence and risk factors for postpartum anovulatory condition in dairy cows. J. Dairy Sci. 90:315-324. https://doi.org/10.3168/jds.S0022-0302(07)72632-2.

Wiltbank, M. C., G. M. Baez, A. Garcia-Guerra, M. Z. Toledo, P. L. J. Monteiro, L. F. Melo, J. C. Ochoa, J. E. P. Santos, and R. Sartori. 2016. Pivotal periods for pregnancy loss during the first trimester of gestation in lactating dairy cows. Theriogenology 86:239-253. https://doi.org/10.1016/j.theriogenology.2016.04.037.

Wiltbank, M. C., A. P. Cunha, A. H. Souza, H. Lopez, R. Sartori, A. Gumen, C. Piccinato, and S. Sangsritavong. 2008. Mechanisms underlying the effect of milk production on duration of estrus and other reproductive traits in lactating dairy cows. Reprod. Domest. Anim. 43:20.

Wiltbank, M. C., A. Gumen, and R. Sartori. 2002. Physiological classification of anovulatory conditions in cattle. Theriogenology 57:2152. https://doi.org/10.1016/S0093-691X(01)00656-2.

Ylioja, C. M., M. M. Rolf, L. K. Mamedova, and B. J. Bradford. 2019. Associations between body condition score at parturition and microRNA profile in colostrum of dairy cows as evaluated by paired mapping programs. J. Dairy Sci. 102:11609-11621. https:// doi.org/10.3168/jds.2019-16675.

Zhang, J., L. X. Deng, H. L. Zhang, G. H. Hua, L. Han, Y. Zhu, X. J. Meng, and L. G. Yang. 2010. Effects of parity on uterine involution and resumption of ovarian activities in postpartum Chinese Holstein dairy cows. J. Dairy Sci. 93:1979-1986. https://doi.org/ 10.3168/jds.2009-2626.

\section{ORCIDS}

D. Manríquez @ https://orcid.org/0000-0003-0899-2457

W. W. Thatcher (1) https://orcid.org/0000-0001-6866-3431

J. E. P. Santos $\odot$ https://orcid.org/0000-0003-3403-1465

R. C. Chebel ๑ https://orcid.org/0000-0002-9700-8089

K. N. Galvão @ https://orcid.org/0000-0002-6683-4476

G. M. Schuenemann (ㅇ https://orcid.org/0000-0003-1114-4512

R. C. Bicalho @ https://orcid.org/0000-0003-4680-1981

R. O. Gilbert (ㄴ) https://orcid.org/0000-0002-1528-243X

S. Rodriguez-Zas @ https://orcid.org/0000-0003-1122-4758

G. J. M. Rosa (i) https://orcid.org/0000-0001-9172-6461

P. Pinedo @ https://orcid.org/0000-0001-7111-3377 